\title{
Pharmacotherapy for Comorbid Adult Attention-Deficit Hyperactivity Disorder and Stimulant Dependence: A Systematic Review
}

\author{
Woon LS ${ }^{\mathrm{a}, \mathrm{b}}$, Hazli Z $\mathrm{Z}^{\mathrm{a}}$, Gan LLYc \\ ${ }^{a}$ Department of Psychiatry, Universiti Kebangsaan Malaysia Medical Centre, Kuala Lumpur \\ ${ }^{b}$ Hospital Bahagia Ulu Kinta, Tanjung Rambutan, Perak \\ 'Department of Pharmacy, Universiti Kebangsaan Malaysia Medical Centre, Kuala Lumpur
}

\begin{abstract}
Comorbid adult attention-deficit hyperactivity disorder (ADHD) and stimulant dependence is widely recognized, but efficacy of pharmacotherapy in this patient population is not well established. We aimed to review whether pharmacotherapy is efficacious in reducing ADHD symptoms and stimulant use in comorbid adult ADHD and stimulant use disorder. English articles until June 2017 were systematically searched in electronic databases (MEDLINE and PsycINFO), an online clinical trials register (ClinicalTrial.gov), and through hand-search of article references. Randomized, double-blind, placebo-controlled trials that studied efficacy of pharmacotherapy in adults with comorbid ADHD and stimulant dependence were included. Two reviewers assessed studies for inclusion and extracted data; disagreements were resolved by consensus. Study outcomes included were changes in ADHD symptom severity, substance abstinence, treatment retention rates and safety. From the 1394 records identified, five trials $(n=358)$ were included. Four studies involved methylphenidate; in another study extended-release mixed amphetamine were used. The comorbid stimulant was cocaine in three studies, and amphetamines in the rest. All were short-term studies involving predominantly young male adults conducted in outpatient settings. There is early promising but mixed evidence for therapeutic efficacy in improving ADHD symptoms. Stimulant medications did not worsen stimulant dependence or adverse effects of stimulant medications. Side effects were mild and tolerable. High attrition rates and small sample size limited the generalizability of findings. Current limited evidence suggests that stimulant treatment for comorbid adult ADHD and stimulant dependence is feasible. Welldesigned trials with adequate power are needed for more robust evidence on ADHD and stimulant use outcomes.
\end{abstract}

KEYWORDS: Attention-deficit hyperactivity disorder, adult, pharmacotherapy, stimulant dependence

\section{INTRODUCTION}

Attention-deficit hyperactivity disorder (ADHD) is a clinical entity characterized by increased levels of hyperactive, impulsive and inattentive behaviours beginning in early childhood. Until recent times, it was assumed that most ADHD cases would resolve when the children grow up. ${ }^{1}$ However, it is now

Corresponding author :

Dr. Hazli Zakaria

Department of Psychiatry, UKM Medical Centre

Jalan Yaacob Latif, Bandar Tun Razak,

56000 Cheras, Kuala Lumpur, Malaysia

Tel: +603-91456142 Fax: +603-91456681

E-mail: hazliz@ppukm.ukm.edu.my known that ADHD persist into adulthood in many patients. About $15 \%$ of children with ADHD were found to have retained the full diagnosis by age 25 years in a meta-analysis by Faraone and colleagues. ${ }^{2}$ Epidemiological studies have given the estimations of the prevalence of adult ADHD in the range of 3\% to $5 \%,{ }^{3-4}$ while a more recent meta-analysis estimated a pooled prevalence of $2.5 \%$ of the general population. ${ }^{5}$

ADHD patients are more often addicted to drugs and alcohol than general population. About $15 \%$ to $25 \%$ of drug addicts and alcoholics have current ADHD. ${ }^{6,7}$ It has been observed that adults with ADHD and substance use disorders (SUD) have an earlier onset 
of substance use compared to adults without ADHD. ${ }^{8}$ Moreover, SUD has been reported to be more severe in adults with ADHD relative to those without ADHD. ${ }^{7}$ In particular, a greater likelihood of stimulant dependence may be found among individuals with adult ADHD. ${ }^{9}$ Impulsivity, which is a key feature of $A D H D$, can be an important contributing factor to the onset of substance misuse and subsequent dependence. ${ }^{10}$ High rates of illicit substance use among adults with ADHD can also represent a form of self-medication. ${ }^{11}$

Both stimulants and non-stimulant medications have been proven effective in adult ADHD. A metaanalysis by Mészáros and colleagues in 2009 showed that the pooled effect size of pharmacotherapy for adult ADHD was in the medium-to-high range, with the effect size for stimulants slightly higher as opposed to non-stimulant medications. ${ }^{12}$ While the number of available clinical trials in this field is relatively small, several reviews on pharmacotherapy for comorbid adult ADHD and substance dependence have been published. ${ }^{13-15}$ In general, they have shown that medications for ADHD are reasonably safe to be used in this patient population, with comparable efficacy in treating ADHD symptoms in short term and probably longer term, as well as beneficial albeit less conclusive effects on the comorbid substance use.

Nonetheless, specific review of studies on pharmacotherapy for comorbid adult ADHD and stimulant use is still wanting. There are several specific considerations with regard to pharmacotherapy in this subset of patients. Keeping in mind that the mainstay of treatment for ADHD is stimulants, prior exposure to illicit stimulant drugs can potentially result in sensitization to stimulant medications, hence increased chance of poor tolerability. ${ }^{16}$ On the other hand, while stimulants of abuse do share similar biochemical pathways and mechanisms with stimulant medications, a crucial difference between these two is that illicit stimulants, such as amphetamines and cocaine, produce pulsatile release of dopamine and hence highly reinforcing pleasurable effects, in contrast to the tonic, regular firing of dopamine effected by stimulant medications, which have more sustained action. ${ }^{17}$ Thus, can stimulant-dependent ADHD patients, who are accustomed to rapid surge of dopamine release in the brain reward system, actually experience attenuated therapeutic effect when they are treated with stimulant medications, analogous to the diminished rewards experienced by drug-dependent individuals during ordinary pleasurable activities? Contrarily, as one possible reason of illicit stimulant use is self-medication, ADHD treatment may well have the potential to reduce stimulant abuse.

With the objective to examine pharmacological treatment in adults with comorbid ADHD and stimulant use disorder, we reviewed randomized, controlled trials (RCTs) that assessed the efficacy of ADHD medications in improving ADHD symptoms and reducing illicit stimulant use in this patient population.

\section{MATERIALS AND METHODS}

We sought to identify all RCTs comparing active pharmacological interventions with placebo in the treatment for comorbid adult ADHD and stimulant (amphetamines or cocaine) dependence according to Diagnostic and Statistical Manual of Mental Disorders, Fourth Edition (DSM-IV) criteria. No restrictions on publication date or publication status were imposed. Only full articles in the English language were included. Non-randomized trials (e.g. naturalistic studies, clinical audits), open-label trials and review papers were excluded. The participants were both males and females, with the age limit of 18 to 65 years. Studies that have recruited both adult and adolescent participants were not included. Studies involving participants with additional substance abuse or dependence were also excluded. Both fixed and flexible dose designs for the active pharmacological agents were allowed. Concurrent non-pharmacological interventions given to participants in both active treatment and placebo arms were permitted.

The main outcomes were changes in ADHD symptom severity and substance abstinence. Changes in ADHD symptoms severity were assessed using both selfand observer-rated scales for adult ADHD, whenever available in the included studies. Certain ADHD symptoms are readily assessable through objective ratings (e.g. inattention during conversation), whereas certain symptoms, such as inner restlessness, rely mostly on subjective report, particularly among adult patients. ${ }^{18}$ Abstinence from stimulants was primarily assessed by measurements based on negative urine samples. Urine sample 
results were deemed more objective and demonstrable measurement of stimulant use as compared to self-report or assessments on craving. Secondary outcome measures were treatment retention rates and safety. Retention rate was defined as the proportion of participants remained in the study at its completion. Retention rates were extracted or calculated from the data provided in the included articles for all treatment arms. Safety of pharmacological treatments was assessed by reviewing the most common adverse events as well as serious adverse events reported in these articles. To identify relevant studies, electronic databases including MEDLINE and PsycINFO were searched from the inception of the databases up to June 2017 through the search engine Ovid. Search was also conducted at ClinicalTrials.gov, the clinical trial registry maintained by the National Library of Medicine of the United States to look for registered but unpublished or ongoing trials. In addition, checking of article reference lists were done to look for other relevant articles. We used the following search terms to search all databases and trial register: adult; attention deficit hyperactivity disorder; attention deficit disorder; ADHD; substance use disorder; substance abuse; substance dependence; amphetamine*; methamphetamine*; cocaine; pharmacotherapy; medication*; treatment; stimulant*; and atomoxetine. Full research strategy is reported in Appendix 1.

Assessment for eligibility of studies for inclusion in this review was independently performed by two researchers ( $\mathrm{LW}$ and $\mathrm{HZ}$ ). Initial elimination of articles was done through screening of titles and abstracts of all identified records. The remaining articles were examined in full subsequently to assess for eligibility. At both stages, disagreements between researchers were resolved by consensus.

To ascertain the risk of bias in the individual eligible randomized trials, two out of the three reviewers ( $\mathrm{LW}, \mathrm{HZ}$ and $\mathrm{LG}$ ) worked independently to determine the adequacy of random sequence generation, allocation concealment, blinding of participants, healthcare providers and outcome assessors, potential attrition bias and reporting bias using the Cochrane risk of bias assessment tool. We also developed a data extraction form based on the Cochrane data collection form for intervention review: RCTs only, version 3 (available at: http:// training.cochrane.org/resource/data-collection-formsintervention-reviews). It was pilot-tested on one selected study and consequently modified and simplified. Two reviewers were assigned to extract data from each included study independently. Data extracted included the following: (1) characteristics of trial participants (age, gender, and type of stimulant dependence), and the trial's inclusion and exclusion criteria, recruitment method and setting of the trial; (2) details of interventions (type of medication, dose and duration of treatment, and concurrent treatment given); (3) outcome measures for ADHD severity (objective and/or subjective rating scales), stimulant abstinence (based on negative urine sample), retention rates in study, and adverse events reported. When there were differences of opinion between two reviewers on risk of bias assessment and data extraction for a particular study, the third researcher would review the article and the disagreements were reconciled by majority voice.

\section{RESULTS}

\section{Study selection}

The search of MEDLINE and PsycINFO databases returned a total of 1810 records. Additional five articles were identified from other sources, including one unpublished study from trial registry and four articles from hand search of article reference lists. After removing duplicates, 1394 items remained. Out of this, 1359 studies were removed after review of titles and abstracts as these papers clearly did not meet the eligibility criteria. The full articles of the remaining 35 studies were sought. Further data could not be found for two studies (one study in abstract form only; another was the unpublished study, which was without any enrolment of participants). One duplicate paper was also removed. Two non-English articles and five review papers were excluded as well. The full text of the remaining 25 citations was examined in detail. It appeared that 20 studies did not meet the inclusion criteria as described (eight were open label trials and 12 were non-randomized trials). The remaining five studies that met the inclusion criteria were included in the systematic review (Fig. 1).

\section{General study characteristics}

All five studies included in the final review were randomized, double-blind, placebo-controlled 
clinical trials published in English. In three studies, the stimulant of dependence was cocaine, while in another two studies it was amphetamines. Duration of study ranged from 12 to 24 weeks. Total number of participants in all the included studies was 358 . Majority of the participants was male, consisting $75 \%$ to $100 \%$ of all participants in individual studies. A large proportion of study subjects were Caucasians, with smaller numbers of AfricanAmerican and Hispanics. The mean age across studies was in the late thirties to early forties. All studies were conducted in outpatient settings. The pharmacological agents used in the included studies consisted of only psychostimulants; RCTs using nonstimulant medications were not identified. Methylphenidate (MPH) was used in all studies except for one study on comorbid cocaine dependence, in which extended-release mixed amphetamine salts were the active treatment given. In all studies, concurrent non-pharmacological treatments targeting drug relapse and/or ADHD symptoms were also administered to participants in both active treatment and placebo arms.

Risk of bias within individual studies assessed using the Cochrane risk of bias assessment tool is presented in Table I. Risk of bias due to incomplete outcome data was considered high for most of the studies because of high attrition rates. Findings of the included studies are summarized in Table II. Further details of the results of the included studies are presented in the following sections on the evidence of treatment for comorbid adult ADHD with amphetamine dependence and comorbid adult ADHD and cocaine dependence, respectively.

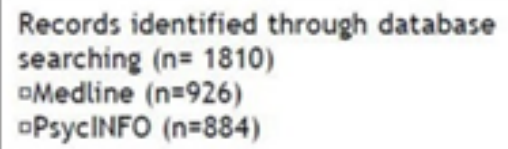

Additional records identified through other sources $(n=5)$

oUnpublished study from trial register $(n=1)$

- Hand search of article references $(n=4)$

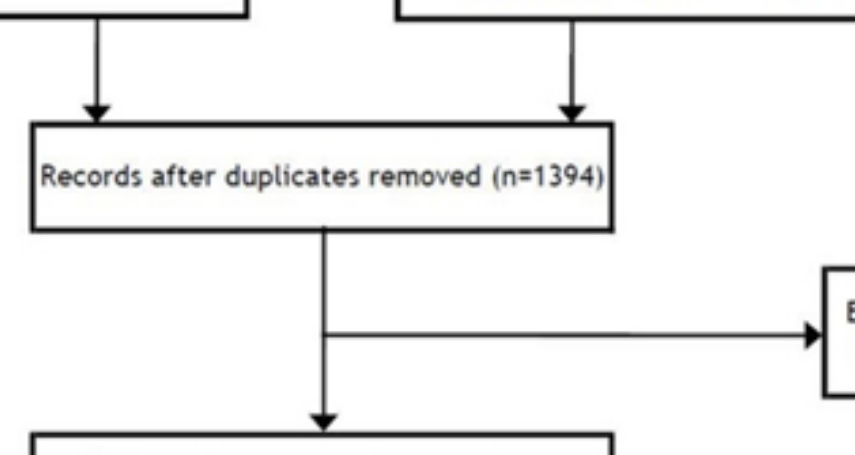

Excluded after initial screen of titles and abstracts $(n=1359)$

Full articles sought and assessed for eligibility $(n=35)$

Studies included in systematic review $(n=5$

Full articles excluded $(n=30)$ Non-English articles $(n=2)$ Reviews ( $n=5$ ) Duplicates $(\mathrm{n}=1)$ Non-randomized trials ( $n=12$ ) Open label trials $(n=8)$ Unable to extract data $(n=2)$

Figure 1: Flow diagram of included and excluded studies through the phases of systematic review 
Table 1. Risk of bias assessment of included studies.

\begin{tabular}{|c|c|c|c|c|c|c|}
\hline Trials & $\begin{array}{c}\text { Random } \\
\text { sequence } \\
\text { generation }\end{array}$ & $\begin{array}{l}\text { Allocation } \\
\text { concealment }\end{array}$ & $\begin{array}{c}\text { Blinding of } \\
\text { participants } \\
\text { and personnel }\end{array}$ & $\begin{array}{l}\text { Blinding of } \\
\text { outcome } \\
\text { assessment }\end{array}$ & $\begin{array}{l}\text { Incomplete } \\
\text { outcome data }\end{array}$ & $\begin{array}{l}\text { Selective } \\
\text { outcome } \\
\text { reporting }\end{array}$ \\
\hline $\begin{array}{l}\text { Konstenius et al. } \\
(2010)^{20}\end{array}$ & Low & Unclear & Low & Low & High & Low \\
\hline $\begin{array}{l}\text { Konstenius et al. } \\
(2014)^{21}\end{array}$ & Low & Low & Low & Low & High & Low \\
\hline Levin et al. (2007) & Unclear & Unclear & Low & Low & High & Low \\
\hline $\operatorname{L}_{28}$ evin et al. (2015) & Low & Low & Low & Low & Unclear & Low \\
\hline $\begin{array}{l}\text { Schubiner et al. } \\
(2002)^{16}\end{array}$ & Low & Low & Low & High & High & Low \\
\hline
\end{tabular}

\section{Comorbid adult ADHD and amphetamine dependence}

There were two identified studies focusing on comorbid adult ADHD and amphetamine dependence. Both studies involved the use of osmotic-release methylphenidate (OROS-MPH; Concerta ${ }^{\circledR}$; ALZA Corporation). OROS-MPH has been demonstrated to be effective for treating noncomorbid ADHD in adults. ${ }^{19,20}$ Treatment with OROS -MPH for adult ADHD was associated with significant reduction in inattention and hyperactivity/ impulsivity and generally well tolerated without serious treatment-emergent adverse events.

Konstenius and colleagues evaluated the efficacy of OROS-MPH among 24 adults (75\% male) with comorbid ADHD and DSM-IV amphetamine dependence in a pilot study with parallel, doubleblind design. ${ }^{21}$ Majority of the participants had chronic amphetamine use (mean duration: 14.1 years) and early onset in drug use (mean age: 14.3 years). Participants were randomized to receive OROS-MPH or placebo for a 12-week period with baseline measurements one week prior to the commencement of treatment. Individual skills training program for ADHD symptoms and relapse prevention of drug use was administered weekly to participants in both treatment arms. OROS-MPH was dosed initially at $18 \mathrm{mg} /$ day and increased to the maximum of $72 \mathrm{mg} /$ day over a period of 10 days. Medication adherence was estimated at $59 \%$ for the OROS-MPH arm, and the most common side effects associated with OROS-MPH were headache and nausea. Reversible blurring of vision reported in one participant. No significant differences were present between participants receiving OROS-MPH and participants receiving placebo in terms of the background variables such as age, sex, means of living, age of onset of drug use or years of amphetamine use. There was significant reduction of self-rated ADHD symptoms over time, regardless of treatment arms. However, no significant betweengroup differences were found in self- or observerrated ADHD symptoms, or urine toxicology for amphetamines, participant self-reported substance use and craving. While showing that OROS-MPH could be used without worsening substance-related measurements, the small sample size limited the power to detect significant between group differences. Improvement of ADHD symptoms over time can be partially attributed to the non-specific effects of intensive outpatient consultation and skill training programme provided to all participants.

Konstenius et al. subsequently examined the use of OROS-MPH among 54 adult males who fulfilled DSMIV criteria for ADHD and amphetamine dependence and were recruited from three prisons in Sweden and enrolled in a 24-week, placebo-controlled trial. ${ }^{22}$ All subjects were released on supervised probation during the study period. OROS-MPH was started at 18 $\mathrm{mg} /$ day, titrated over a period of 19 days to a 
maximum dose of $180 \mathrm{mg} /$ day. Once-weekly manual-based cognitive behavioural therapy (CBT) targeting relapse prevention was also administered as co-treatment for both treatment arms during the first 12 weeks of the study. The proportion of participants who continued medication until study completion was low (29.6\% for OROS-MPH and $7.4 \%$ for placebo). Adverse effects experienced included anorexia, headache, abdominal discomfort, sleep problem and sweating. There were significant differences in self-rated ADHD symptom scores and Clinical Global Impression-Severity (CGI-S) scores between OROS-MPH and placebo groups, but no significant difference between the treatment groups in clinician-rated improvement in CGI-I scores (Clinical Global Impression-Improvement). The two treatment groups did not differ with regard to craving at completion of study (week 24). However, proportion of amphetamine-negative urine was significantly higher in the OROS-MPH group. This study demonstrated that OROS-MPH in higher-thanusual doses up to $180 \mathrm{mg} /$ day could be used safely and effectively to treat ADHD and prevent relapse in individuals with a co-diagnosis of ADHD and amphetamine dependence.

\section{Comorbid adult ADHD and cocaine dependence}

The effectiveness of immediate-release MPH among adults with comorbid ADHD and cocaine dependence (meeting DSM-IV criteria) was evaluated by Schubiner and colleagues. ${ }^{16}$ Forty eight cocainedependent adults (90\% males) with comorbid ADHD participated in a 13-week (with baseline measurements at week 1 and 12 weeks of treatment), double-blind, placebo-controlled parallel study. Participants were recruited through advertisements in local newspapers and radio broadcasts. An initially planned third arm with pemoline, a central nervous system stimulant drug of the 4-oxazolidinone class, was abandoned after a year into the study due to recruitment difficulties. $\mathrm{MPH}$ was dosed at $10 \mathrm{mg}$ three times a day for two to three days, $20 \mathrm{mg}$ three times per day for the next four to five days, and $30 \mathrm{mg}$ three times per day by Day 8 of study. Twice weekly group CBT for cocaine dependence plus weekly individual CBT sessions for ADHD symptoms was provided. Difference in retention rates between the treatment arms was not significant. Insomnia was more common among participants on MPH. Elevated blood pressure and disorientation was reported in one patient on $\mathrm{MPH}$, respectively. These adverse effects resolved after dose reduction. There was no treatment discontinuation due to side effects in the MPH arm. While physician-rated and self-rated efficacy indexes assessing degree of improvement revealed significantly greater ADHD symptom relief in the MPH group, there was no significant difference in both inattentive and hyperactive symptoms using patient-rated ADHD Symptom Checklist between the treatment groups. No group differences in proportion of cocaine-negative urine sample $(42 \%$ for the placebo group vs. $50 \%$ for the MPH group), self-reported cocaine use, or cocaine craving. It is possible that the small sample size did not have adequate power to detect treatment effects.

Levin and colleagues also examined the impact of $\mathrm{MPH}$ in this patient population in a double-blind, placebo-controlled, randomized trial. ${ }^{23} \mathrm{~A}$ total of 106 adult participants (83\% male) with DSM-IV ADHD and DSM-IV cocaine dependence were treated with methylphenidate for 14 weeks (including a placebo lead-in phase for one week, a dose titration phase for two weeks followed by stable dose for 11 weeks). Immediate-release methylphenidate was initiated at $10 \mathrm{mg} /$ day and increased up to $40 \mathrm{mg} /$ day at twice daily dosing. Subsequently, it was replaced by the sustained-release formulation, which was further escalated up to $60 \mathrm{mg} /$ day. Completion of treatment at 14 weeks was $43 \%$ for $\mathrm{MPH}$ and $45 \%$ for placebo, indicating rather high levels of attrition across both treatment arms.

Common adverse events reported were headache, insomnia, and gastrointestinal symptoms. All participants also received weekly individual CBT with structured relapse prevention manual modified for individuals with ADHD. Subjects in the two treatment groups did not differ significantly in ADHD symptoms based on Adult ADHD Rating Scale (AARS), Targeted Adult Attention Deficit Disorder Scale (TAADDS) and CGI ADHD improvement score. While the mean proportions of cocaine-positive weeks for both groups were similar (MPH: 73\%; Placebo: 70\%), ADHD responders (assessed using TAADDS) in the $M P H$ arm were found to have significantly lower proportion of cocaine positive urines.

Even though amphetamines were among the first agents shown to be effective in the management of $\mathrm{ADHD},{ }^{24}$ legitimate concerns about diversion and 
abuse potential have for a long time limited their value in treating symptoms of ADHD. ${ }^{25}$ The availability of extended-release formulation of mixed amphetamine salts with more desirable longacting property thus allows greater use of this group of agents. The efficacy of mixed amphetamine salts in the general adult ADHD population has been supported by a number of randomized controlled trials. ${ }^{26,27}$ Open-label follow-up up to 24 months has also shown that it was well tolerated in longer term. ${ }^{28}$

The efficacy of extended-release mixed amphetamine salts (60 mg/day and $80 \mathrm{mg} /$ day) was evaluated by Levin and colleagues among patients seeking treatment for cocaine dependence through local advertisements or clinical referrals. ${ }^{29}$ In all, 126 adults (84\%male) with DSM-IV ADHD and DSM-IV current cocaine dependence were randomized to receive $60 \mathrm{mg} /$ day extended-release mixed amphetamine salts or $80 \mathrm{mg} /$ day extended-release mixed amphetamine salts + CBT/relapse prevention treatment, and placebo $+\mathrm{CBT} /$ relapse prevention treatment for 14-week (with one week placebo lead -in period) in this three-arm parallel controlled trial. Mean medication adherence estimated from self-reported pill intake was $98.8 \%$, while median rates were not significantly different across treatment arms. There were significantly higher odd ratios (ORs) for response ( $\geq 30 \%$ reduction) using Adult ADHD Investigator Symptom Rating Scale (AISRS) score for both $80 \mathrm{mg}$ and $60 \mathrm{mg}$ mixed amphetamine salts against placebo.

Significant differences were also found comparing the active treatments with placebo using CGI subscale for ADHD and Conners' Adult ADHD Observer-Rating Scale (CAARS:0). However, no significant difference was found between the $80 \mathrm{mg}$ and $60 \mathrm{mg}$ groups. Reduction of cocaine use in the active treatment arms $(80 \mathrm{mg}, 60 \mathrm{mg}$, and pooled $80 \mathrm{mg}$ and $60 \mathrm{mg}$ vs. placebo) was demonstrated by significantly higher ORs for proportions of cocaine abstinence in the last 3 weeks, as well as reduction in the proportion of cocaine positive weeks. Moderate to severe adverse events include anxiety and insomnia. Participant medication discontinuation rates did not differ among the treatment groups. The authors concluded that extended-release mixed amphetamine salts could be given safely to ADHD patients with comorbid cocaine dependence. Of note, treatment retention rates were high for both $60 \mathrm{mg} /$ day and $80 \mathrm{mg} /$ day mixed amphetamine salts $(75 \%$ and $79 \%$ respectively), and higher than the placebo arm (67\%).

\section{DISCUSSIONS}

\section{Summary of evidence}

Psychostimulants, including both immediate- and extended-release (OROS) MPH as well as mixed amphetamine salts have been studied in RCTs among adults with comorbid ADHD and stimulant dependence. Between the two studies of OROS-MPH for amphetamine dependence, in the earlier pilot study OROS-MPH did not reduce primary ADHD and substance use outcomes, while in the subsequent study that involved a longer duration (24 weeks) and higher maximum MPH dose, OROS-MPH (180mg/day) significantly improved ADHD symptoms as well as amphetamine use outcome.

This may indicate that higher doses of stimulant drugs with longer duration of treatment may be necessary for this particular patient population. In cocaine-dependent subjects, immediate-release MPH improved subjective ratings of ADHD symptoms but not in objective evaluation, and had no effects on cocaine use. Similarly, OROS-MPH was not found to improve overall $A D H D$ and cocaine use symptoms, though ADHD symptom responders did show reduced cocaine use. On the other hand, extended-release mixed amphetamine salts appeared to alleviate ADHD symptoms and decrease cocaine use, with both $60 \mathrm{mg}$ and $80 \mathrm{mg}$ preparations producing similar effects. In general, pharmacotherapy for adult ADHD in patients with comorbid stimulant dependence was well tolerated. Stimulant medications were not shown to worsen illicit substance use, with some results to suggest that higher doses of $\mathrm{MPH}$ and extended-release amphetamine salts may significantly improve stimulant use outcomes. Comparing to the large effect sizes that were found from studies of $\mathrm{MPH}^{30}$ and amphetamine salts ${ }^{26}$ in general adult ADHD population, the findings on ADHD symptoms for patients with comorbid stimulant use were rather mixed. Based on the limited evidence available, it appears that ORS-MPH at doses higher than the recommended range was efficacious in ADHD patients with amphetamine dependence, while extended-release mixed amphetamine salts produced better outcomes among cocaine users. 
Table II: Summary of findings of included trials.

\begin{tabular}{|c|c|c|c|c|c|c|c|c|c|c|c|}
\hline \multirow{2}{*}{$\begin{array}{l}\text { Author } \\
\text { (year) }\end{array}$} & \multirow{2}{*}{$\begin{array}{l}\text { Partici- } \\
\text { pants } \\
(n), \\
\text { male } \\
\text { propor- } \\
\text { tion }\end{array}$} & \multirow{2}{*}{$\begin{array}{l}\text { Mean } \\
\text { age, } \\
\text { years } \\
\text { (SD) }\end{array}$} & \multirow{2}{*}{ Setting } & \multirow{2}{*}{$\begin{array}{c}\text { Comorbid } \\
\text { stimulant } \\
\text { use disor- } \\
\text { der }\end{array}$} & \multirow{2}{*}{$\begin{array}{l}\text { Medica- } \\
\text { tion", } \\
\text { duration }\end{array}$} & \multirow{2}{*}{$\begin{array}{l}\text { Dose/ } \\
\text { dose } \\
\text { range }\end{array}$} & \multirow{2}{*}{$\begin{array}{l}\text { Concurrent } \\
\text { treatment }\end{array}$} & \multirow{2}{*}{$\begin{array}{l}\text { Retention } \\
\text { rate* }^{*}\end{array}$} & \multicolumn{2}{|c|}{ Main outcomes } & \multirow{2}{*}{$\begin{array}{l}\text { Adverse } \\
\text { events } \dagger\end{array}$} \\
\hline & & & & & & & & & ADHD & SUD & \\
\hline $\begin{array}{l}\text { Konsteni } \\
\text { us et al. } \\
(2010)^{20}\end{array}$ & $24,75 \%$ & $\begin{array}{l}37.4 \\
(9.9)\end{array}$ & $\begin{array}{l}\text { Outpatient } \\
\text { addition } \\
\text { units in } \\
\text { the } \\
\text { Stockholm } \\
\text { metropoli- } \\
\text { tan region }\end{array}$ & $\begin{array}{l}\text { Ampheta- } \\
\text { mines }\end{array}$ & $\begin{array}{l}\text { OROS- } \\
\text { MPH, } 13 \\
\text { weeks }\end{array}$ & $\begin{array}{l}18 \mathrm{mg} / \\
\text { day- } \\
72 \mathrm{mg} / \\
\text { day }\end{array}$ & $\begin{array}{l}\text { Once } \\
\text { weekly } \\
\text { individual } \\
\text { skills } \\
\text { training } \\
\text { program } \\
\text { targeting } \\
\text { relapse in } \\
\text { drug use } \\
\text { and ADHD } \\
\text { symptoms }\end{array}$ & $\begin{array}{l}\text { MPH 59\%; } \\
\text { Placebo } \\
84 \%\end{array}$ & $\begin{array}{l}\text { No } \\
\text { significant } \\
\text { difference } \\
\text { between } \\
\text { treatment } \\
\text { arms in } \\
\text { self-rated } \\
\text { (CAARS:SV) } \\
\text { and } \\
\text { observer- } \\
\text { rated } \\
\text { (CAARS:0) } \\
\text { ADHD } \\
\text { symptoms }\end{array}$ & $\begin{array}{l}\text { No } \\
\text { difference } \\
\text { in drug use } \\
\text { (self-report } \\
\text { and urine } \\
\text { toxicology), } \\
\text { and craving } \\
\text { between } \\
\text { treatment } \\
\text { arms }\end{array}$ & $\begin{array}{l}\text { Most } \\
\text { common: } \\
\text { headache } \\
\text { and } \\
\text { nausea. } \\
\text { Reversible } \\
\text { blurring } \\
\text { of vision } \\
\text { reported } \\
\text { in one } \\
\text { partici- } \\
\text { pant. }\end{array}$ \\
\hline $\begin{array}{l}\text { Konsteni } \\
\text { us et al. } \\
(2014)^{21}\end{array}$ & $54,100 \%$ & $\begin{array}{l}\text { MPH 41 } \\
\text { (7.5); } \\
\text { Placebo } \\
42(11.7)\end{array}$ & $\begin{array}{l}\text { Outpatient } \\
\text { (subjects } \\
\text { on } \\
\text { probation } \\
\text { from 3 } 3 \\
\text { medium- } \\
\text { security } \\
\text { prisons in } \\
\text { Stockholm, } \\
\text { Sweden) }\end{array}$ & $\begin{array}{l}\text { Ampheta- } \\
\text { mines }\end{array}$ & $\begin{array}{l}\text { OROS- } \\
\text { MPH, } 24 \\
\text { weeks }\end{array}$ & $\begin{array}{l}\text { 18mg/ } \\
\text { day - } \\
180 \mathrm{mg} / \\
\text { day }\end{array}$ & $\begin{array}{l}\text { Manual- } \\
\text { based CBT } \\
\text { sessions } \\
\text { targeting } \\
\text { relapse for } \\
\text { the first } \\
12 \text { weeks }\end{array}$ & $\begin{array}{l}\text { MPH } \\
29.6 \% \text {; } \\
\text { Placebo } \\
7.4 \%\end{array}$ & $\begin{array}{l}\text { Treatment } \\
\text { with MPH } \\
\text { significantly } \\
\text { reduced all } \\
\text { ADHD } \\
\text { symptoms } \\
\text { compared } \\
\text { to placebo } \\
\text { based on } \\
\text { CAARS:SV }\end{array}$ & $\begin{array}{l}\text { Significant } \\
\text { difference } \\
\text { in median } \\
\text { proportion } \\
\text { of } \\
\text { ampheta- } \\
\text { mine- } \\
\text { negative } \\
\text { urine } \\
\text { (MPH: } 23 \% ; \\
\text { Placebo: } \\
14 \% \text { ); no } \\
\text { difference } \\
\text { in craving }\end{array}$ & $\begin{array}{l}\text { Most } \\
\text { common } \\
\text { were loss } \\
\text { of } \\
\text { appetite, } \\
\text { headache, } \\
\text { abdominal } \\
\text { discom- } \\
\text { fort, } \\
\text { sleep } \\
\text { problem } \\
\text { and } \\
\text { sweating }\end{array}$ \\
\hline $\begin{array}{l}\text { Levin et } \\
\text { al. } \\
(2007)^{22}\end{array}$ & $106,83 \%$ & $\begin{array}{l}37, \text { range } \\
23-52\end{array}$ & $\begin{array}{l}\text { Outpatient } \\
\text { in New } \\
\text { York city }\end{array}$ & Cocaine & $\begin{array}{l}\text { Tmmediate } \\
\text { - and } \\
\text { sustained } \\
\text { - release } \\
\text { MPH }\end{array}$ & $\begin{array}{l}\text { 10mg/ } \\
\text { day- } \\
60 \mathrm{mg} / \\
\text { day }\end{array}$ & $\begin{array}{l}\text { Weekly } \\
\text { individual } \\
\text { CBT with } \\
\text { structured } \\
\text { relapse } \\
\text { prevention } \\
\text { manual } \\
\text { modified for } \\
\text { individuals } \\
\text { with ADHD }\end{array}$ & $\begin{array}{l}\text { MPH } \\
43.4 \% ; \\
\text { Placebo } \\
45.3 \%\end{array}$ & $\begin{array}{l}\text { No significant } \\
\text { difference } \\
\text { in ADHD } \\
\text { symptoms } \\
\text { based on } \\
\text { AARS and } \\
\text { TAADDS }\end{array}$ & $\begin{array}{l}\text { No } \\
\text { significant } \\
\text { difference } \\
\text { in mean } \\
\text { proportion } \\
\text { of } \\
\text { cocaine- } \\
\text { positive } \\
\text { weeks } \\
\text { (MPH: 73\%; } \\
\text { Placebo: } \\
70 \%)\end{array}$ & $\begin{array}{l}\text { Most } \\
\text { common } \\
\text { adverse } \\
\text { events } \\
\text { headache, } \\
\text { gastroin- } \\
\text { testinal } \\
\text { upset, } \\
\text { diarrhoea } \\
\text { and } \\
\text { insomnia }\end{array}$ \\
\hline $\begin{array}{l}\text { Levin et } \\
\text { al. } \\
(2015)^{28}\end{array}$ & $126,84 \%$ & $\begin{array}{l}60 \mathrm{mg} \\
\text { group } \\
43.90 \\
(7.45) ; \\
\text { 80mg } \\
\text { group } \\
38.37 \\
(8.56) ; \\
\text { Placebo } \\
39.26 \\
(7.42)\end{array}$ & $\begin{array}{l}\text { Outpatient } \\
\text { at } \\
\text { Columbia } \\
\text { University/ } \\
\text { New York } \\
\text { State } \\
\text { Psychiatric } \\
\text { Institute or } \\
\text { University } \\
\text { of } \\
\text { Minnesota }\end{array}$ & Cocaine & $\begin{array}{l}\text { Extended } \\
\text {-release } \\
\text { mixed } \\
\text { ampheta- } \\
\text { mine } \\
\text { salts, } 14 \\
\text { weeks }\end{array}$ & $\begin{array}{l}\text { 60mg/ } \\
\text { day and } \\
80 \mathrm{mg} / \\
\text { day }\end{array}$ & $\begin{array}{l}\text { Weekly } \\
\text { CBT/ } \\
\text { relapse } \\
\text { prevention } \\
\text { treatment }\end{array}$ & $\begin{array}{l}60 \mathrm{mg} / \mathrm{d} \\
75 \% ; \\
80 \mathrm{mg} / \mathrm{d} \\
79 \% ; \\
\text { Placebo } \\
67 \%\end{array}$ & $\begin{array}{l}\text { Significantly } \\
\text { higher ORs } \\
\text { for } \geq 30 \% \\
\text { reduction in } \\
\text { AlSRS score } \\
\text { for } 80 \mathrm{mg} \text { vs. } \\
\text { Placebo (OR: } \\
2.27,95 \% \mathrm{Cl} \text {, } \\
0.94-5.49 \text { ) } \\
\text { and } 60 \mathrm{mg} \text { vs. } \\
\text { Placebo (OR: } \\
5.23,95 \% \mathrm{Cl} \text {, } \\
1.98-13.85)\end{array}$ & $\begin{array}{l}\text { Significant- } \\
\text { ly higher } \\
\text { ORs for } \\
\text { proportions } \\
\text { of cocaine } \\
\text { abstinence } \\
\text { in the last } 3 \\
\text { weeks for } \\
80 \mathrm{mg}, 60 \mathrm{mg} \\
\text { and pooled } \\
80 \mathrm{mg} \text { and } \\
60 \mathrm{mg} \text { vs. } \\
\text { placebo }\end{array}$ & $\begin{array}{l}\text { Dry mouth } \\
\text { often in } \\
\text { the mixed } \\
\text { ampheta- } \\
\text { mine } \\
\text { salts } \\
\text { groups; } \\
\text { moderate } \\
\text { to severe } \\
\text { adverse } \\
\text { events: } \\
\text { insomnia } \\
\text { and } \\
\text { anxiety }\end{array}$ \\
\hline $\begin{array}{l}\text { Schubine } \\
\text { r et al. } \\
(2002)^{16}\end{array}$ & $48,90 \%$ & $\begin{array}{l}\text { MPH } \\
38.3 \\
(6.3) ; \\
\text { Placebo } \\
35.8 \\
(6.8)\end{array}$ & $\begin{array}{l}\text { Participants } \\
\text { recruited } \\
\text { through } \\
\text { advertise- } \\
\text { ments at } \\
\text { undisclosed } \\
\text { location(s) }\end{array}$ & Cocaine & $\begin{array}{l}\text { Tmmedi- } \\
\text { ate- } \\
\text { release } \\
\text { MPH, } 13 \\
\text { weeks }\end{array}$ & $\begin{array}{l}\text { 30mg/ } \\
\text { day - } \\
90 \mathrm{mg} / \\
\text { day }\end{array}$ & $\begin{array}{l}\text { Twice } \\
\text { weekly } \\
\text { group CBT } \\
\text { for co- } \\
\text { caine } \\
\text { depend- } \\
\text { ence; } \\
\text { weekly } \\
\text { individual } \\
\text { CBT ses- } \\
\text { sions for } \\
\text { ADHD } \\
\text { symptoms }\end{array}$ & $\begin{array}{l}\text { MPH 45\%; } \\
\text { Placebo } \\
58 \%\end{array}$ & $\begin{array}{l}\text { No group } \\
\text { difference in } \\
\text { ADHD } \\
\text { symptoms } \\
\text { using ADHD } \\
\text { Symptom } \\
\text { Checklist; } \\
\text { significant } \\
\text { effect of } \\
\text { MTP on } \\
\text { subjective } \\
\text { rating of } \\
\text { ADHD } \\
\text { symptoms }\end{array}$ & $\begin{array}{l}\text { No } \\
\text { statistical } \\
\text { difference } \\
\text { in the } \\
\text { proportion } \\
\text { of } \\
\text { cocaine- } \\
\text { negative } \\
\text { urine } \\
\text { sample } \\
\text { (MPH: } 0.50 \\
\text { [SD: } 0.50] \text {; } \\
\text { Placebo: } \\
0.42 \text { [SD: } \\
0.32] \text { ] }\end{array}$ & $\begin{array}{l}\text { Most } \\
\text { common: } \\
\text { anxiety, } \\
\text { sadness, } \\
\text { insomnia, } \\
\text { irritability, } \\
\text { anorexia, } \\
\text { day- } \\
\text { dreaming. } \\
\text { Increased } \\
\text { BP in } 1 \\
\text { patient, } \\
\text { disorien- } \\
\text { tation in } \\
\text { another }\end{array}$ \\
\hline
\end{tabular}

Notes:

Active intervention arm(s); all comparators were placebo; *Retention rates at the end of study; † Adverse effects in the active intervention arm(s)

Abbreviations:

AARS: Adult ADHD Rating Scale; ADHD: Attention-deficit hyperactivity disorder; AISRS: Adult ADHD Investigator Symptom Rating Scale; BP: Blood pressure; CAARS:O: Conners' Adult ADHD Observer-Rating Scale; CAARS:SV: Conners' Adult ADHD Self-Rating Scale; CBT: Cognitive behavioural therapy; CGI-I: Clinical Global Impression-Improvement; CI: Confidence interval; MPH: Methylphenidate; OR: Odds ratio; OROS-MPH: Osmotic release oral system-Methylphenidate; SD: Standard deviation; SUD: Stimulant use disorder; TAADDS: Targeted Adult Attention Deficit Disorder Scale 


\section{Limitations}

\section{Study and outcome level}

All studies included in this review involved small sample size. As a result, they might have inadequate statistical power to detect significant differences between active treatment and placebo arms in terms of ADHD and stimulant use outcomes. At present, only short-term findings for treatment efficacy and tolerability are available. ADHD can run a long unremitting course, with symptoms recognizable until a late age. Similarly, substance dependence, with its resultant long-lasting biochemical and functional alterations in brain, has also been increasingly recognized as a chronic medical illness. ${ }^{31}$ Measurements on long-term outcomes are thus very important. The fact that current studies only lasted for less than half a year makes it difficult to make any conclusion about long -term safety and efficacy of pharmacotherapy in this patient group. A shared weakness observed in the included studies was relatively high attrition rates, which is a common phenomenon among randomized controlled clinical trials. ${ }^{32}$ Because of attrition, the balance in baseline characteristics for randomized study participants may not be maintained in the subgroup that has outcome data, and this may result in biased estimates of the overall effect, reduced statistical power, and restricted generalizability of results. In order to tackle this problem, last observation carried forward (LOCF) was employed in two studies. ${ }^{21,22}$ However, this practice is discouraged because its assumptions are typically inappropriate for central nervous system trials. ${ }^{33}$ Imputation was adopted in another study, ${ }^{29}$ whereas it was unsure how missing data were accounted for in another two studies. The majority of the study subjects were in their late thirties or early forties. This may reflect the fact that clinician awareness of adult ADHD, especially among illicit substance users, was still relatively low, resulting in late diagnosis and treatment. Consequently, findings obtained from these older individuals, with chronic stimulant use, ${ }^{22,}{ }^{23}$ may not be generalizable to the entire population of comorbid ADHD and stimulant dependence, particularly younger patients with shorter history of stimulant dependence.

As noted by some authors, ${ }^{22,}{ }^{29}$ potential diversion is a real concern with regard to the use of agonists in substance use disorders, in this case, stimulant medications in stimulant dependence. The extended-release forms of stimulants used in clinical trials lack rapid absorption and elimination typical of stimulants of abuse, and are supposed to be associated with less stimulant-like drug effects. ${ }^{34}$ OROS-MPH is also less easy to be administered via a non-oral route, thereby reducing the risk of diversion. While patients' adherence to treatment could be monitored through self-report and biological measurements in trials, it could not be ensured that all study participants took their medication as prescribed. A study that looked into diversion of OROS-MPH among adolescents with comorbid ADHD and substance abuse by Winhusen and colleagues found that diversion of OROS-MPH were not significantly influenced by substance use severity, but the adolescents tended to lose more pills compared to adults with ADHD alone. ${ }^{35}$ Prescribing stimulant medications to individuals with stimulant dependence in the community setting may be associated higher risks of diversion than in the well-controlled environment of clinical trials, and effective strategies for monitoring and limiting risk of diversion will be needed. Hence, this area will have to be examined more carefully in future trials. In trials involving methylphenidate, there were two different formulations used, namely OROS-MPH and immediate-release methylphenidate.

These formulations differ in terms of onset of action and duration of action, which may make it difficult to draw general conclusions about the efficacy of methylphenidate among stimulant abusers with ADHD comorbidity. Konstenius and colleagues advocated a high dose $(180 \mathrm{mg} /$ day) of OROS-MPH, which is 2.5 times the maximum effective dose of $72 \mathrm{mg} /$ day as recommended by the United States Food and Drug Administration (FDA). ${ }^{22}$ While frequency of cardiovascular adverse effects did not appear to be increased with high-dose methylphenidate, the small sample size limited the findings' generalizability, and long-term safety data at high doses are still lacking. Urine toxicology was used the detection of stimulant of abuse to assess abstinence in the trials. There has been concern that methylphenidate may yield a false positive result for amphetamine because of cross-reactivity. ${ }^{36}$ However, there is also counter-argument that urine drug test can accurately differentiate methylphenidate and amphetamines. ${ }^{37}$ Thus, the extent of methylphenidate's effect on the validity of urine drug testing results is uncertain. 


\section{Review level}

While there have been a number of review papers on co-occurring adult ADHD and substance use disorder, ${ }^{13-15}$ to the best of the authors' knowledge the current paper is the first systematic review that specifically examines pharmacotherapy for comorbid adult $\mathrm{ADHD}$ and stimulant dependence. We also identified two RCTs that were not included in the previous reviews. ${ }^{22,29}$ A limitation of our review is the use of just two databases, namely MEDLINE and PsycINFO. Nevertheless, MEDLINE database considered is one of the most comprehensive sources of health care information internationally. ${ }^{38}$ In addition, American Psychological Association's PsycINFO database is also a reliable source, which includes a large percentage of publication records in the field of psychological science. ${ }^{39}$ Authors of the included articles were not contacted for further information, thus precluding the clarification of unclearly reported information or scrutiny of raw study data. Considering the diverse outcomes employed by individual studies included in this review, as well as the considerable risk of attrition bias present in these studies, synthesis of data in the form of meta-analysis was not performed. ${ }^{40}$

\section{CONCLUSIONS}

\section{Implications for practice}

Review of current research shows that pharmacotherapy with psychostimulants for comorbid ADHD and stimulant dependence is feasible and safe. While firm recommendation cannot be made due to the limited amount of evidence, beneficial effects of pharmacological treatment on ADHD symptoms cannot be overlooked in adult with stimulant dependence. Hence, consideration on case-by-case basis is required, with treatment tailored to meet individual's needs. As the coexistence of ADHD symptoms with substance use not only lead to greater severity of illicit substance use, but also may synergistically accentuated other risky behaviours such as sexual and driving-related risks, ${ }^{41}$ it is important to take an individual's psychosocial milieu into account in the management plan in order to provide more holistic treatment. As such, concurrent psychosocial interventions may play a critical role in the management of adults with ADHD, as shown by the general symptomatic improvement seen in the studies included in this review irrespective of treatment arms, and from the moderate to large effect sizes demonstrated from a review of brief, structured, and short-term psychological interventions for adults with ADHD. ${ }^{42}$ Taking into account the beneficial effects of time in treatment on clinical outcomes, extra efforts are necessary to keep patients in treatment program in order to improve their clinical condition.

\section{Implications for research}

Overall, evidence base for pharmacotherapy of adult $\mathrm{ADHD}$ and comorbid stimulant dependence is still very limited. More studies with larger and more representative (i.e. in terms of age group and race/ ethnicity) sample have to be carried out. For instance, majority of the study participants were Caucasians, with a smaller number of AfricanAmericans or Hispanics. There is evidence that Asians may be more susceptible to the cardiovascular and euphoric effects of $d$ amphetamines, ${ }^{43}$ and this could have been missed in the studies reviewed. Thus, research in this field involving more diverse sample will be desirable. Moreover, longer trial period will allow better study of the long-term safety and efficacy of pharmacotherapy. Besides, future trials should better address the issue of high attrition and employ more appropriate strategies such as multiple imputations in order to reduce risk of bias. ${ }^{33}$ Several other outcome measures besides substance abstinence (i.e. negative urine sample for the particular substance), such as dose of illicit stimulant used, quality of life, and improvement in functioning could also be used as the secondary outcome measures.

An interesting pattern among the findings of studies included in this review is that ADHD symptomatic improvement seemed to happen in tandem with reduction of illicit stimulant use. ${ }^{22,29}$ Study by Levin and colleagues also suggested that ADHD symptom response was associated with reduced cocaine use. ${ }^{23}$ It can be postulated that because of the tolerance developed toward illicit stimulants and neuroadaptation to the pulsatile firing they produce in dependent individuals, the pharmacological treatments used to treat adult ADHD in this group of patients have to act effectively as agonist/ substitution therapy for the comorbid stimulant dependence in order to achieve its therapeutic potential for ADHD symptoms. At present, studies on 
substitution therapy for cocaine and amphetamine dependence have not been conclusive. ${ }^{44,45}$ Thus, whether agonist-like therapy for the comorbid stimulant dependence is the key for successful treatment of adult ADHD in individuals with co-occurring disorders remains to be explored.

Atomoxetine is the only non-stimulant medication approved by the FDA for treatment of adult ADHD. ${ }^{46}$ While there are quite a number of studies of atomoxetine for adult ADHD in general, ${ }^{47,48}$ and an RCT in cannabis-dependent subjects, ${ }^{49}$ so far there is only one preliminary open trial studying atomoxetine among cocaine abusers, which demonstrated significant reduction in $A D H D$ symptoms but no significant change in cocaine use, and with high drop-out rates. ${ }^{50}$ Atomoxetine, a norepinephrine reuptake inhibitor, can theoretically produce slow-onset, long-duration norepinephrine transporter inhibition at prefrontal cortex, restoring tonic postsynaptic norepinephrine (NE) and dopamine (DA) signaling. ${ }^{17}$ Consequently, desensitization of postsynaptic NE and DA receptors could be associated with improved ADHD symptoms and reduced substance use. Whether this proposition holds true in the presence of competing illicit stimulant use will be a focus of more research.

Last but not least, as current evidence has demonstrated the vital role of psychosocial interventions in managing comorbid adult ADHD and illicit stimulant use in conjunction with pharmacotherapy, further research into the interplay between various drug treatments and psychological treatment modalities may help to identify the most suitable combinations of pharmacological and non-pharmacological therapies for different subgroups of patients.

\section{CONFLICT OF INTEREST}

The authors declared no potential conflicts of interest with respect to the research, authorship, and/or publication of this article.

\section{ACKNOWLEDGEMENTS}

The authors would like to thank Professor Dr Hatta Sidi, Associate Professor Dr Suriati Mohamed Saini, Associate Professor $\mathrm{Dr}$ Isa Naina Mohamed, and Associate Professor Dr Yee Hway Ann for their assistance and advice in conducting the review and writing the manuscript.

\section{REFERENCES}

1. Hill JC, Schoener EP. Age-dependent decline of attention deficit hyperactivity disorder. Am J Psychiatry 1996; 153: 1143-6.

2. Faraone SV, Biederman J, Mick E. The agedependent decline of attention deficit hyperactivity disorder: a meta-analysis of follow-up studies. Psychological Medicine 2006; 36: 159-65.

3. Kessler RC, Adler LA, Barkley R, et al. The prevalence and correlates of adult ADHD in the United States: results from the National Comorbidity Survey Replication. Am J Psychiatry 2006; 163: 716-23.

4. Fayyad J, De Graaf R, Kessler R, et al. Crossnational prevalence and correlates of adult attention-deficit hyperactivity disorder. $\mathrm{Br} \mathrm{J}$ Psychiatry 2007; 190: 402-9.

5. Simon V, Czobor P, Bálint S, Mészáros A, Bitter I. Prevalence and correlates of adult attentiondeficit hyperactivity disorder: meta-analysis. $\mathrm{Br}$ J Psychiatry 2009; 194: 204-11.

6. Wilens TE, Biederman J, Mick E. 1998. Does ADHD affect the course of substance abuse? Findings from a sample of adults with and without ADHD. Am J Addict 1998; 7: 156-63.

7. Schubiner $\mathrm{H}$, Tzelepis A, Milberger $\mathrm{S}$, et al. Prevalence of attention-deficit/hyperactivity disorder and conduct disorder among substance abusers. J Clin Psychiatry 2000; 61: 244-51.

8. Wilens TE, Biederman J, Mick E, Faraone SV, Spencer, T. Attention deficit hyperactivity disorder (ADHD) is associated with early onset substance use disorders. J Nerv Ment Dis 1997; 185: 475-82.

9. Kaye S, Darke S, Torok M. Attention deficit hyperactivity disorder (ADHD) among illicit psychostimulant users: A hidden disorder? Addiction 2013; 108: 923-31.

10. Crunelle CL, Veltman DJ, Van Emmerik-van Oortmerssen K, Booij J, Van den Brink W. Impulsivity in adult ADHD patients with and without cocaine dependence. Drug Alcohol Depend 2013; 129: 18-24.

11. Wilens TE. Impact of ADHD and its treatment on substance abuse in adults. J Clin Psychiatry 2004; 65: 38-45.

12. Mészáros $\mathrm{A}, \mathrm{C}$ zobor $\mathrm{P}$, Bálint $\mathrm{S}$, et al. 
Pharmacotherapy of adult attention deficit hyperactivity disorder (ADHD): a meta-analysis. Int J Neuropsychopharmacol 2009; 12: 1137-47.

13. Pérez De Los Cobos J, Siñol N, Pérez V, Trujols J. Pharmacological and clinical dilemmas of prescribing in co-morbid adult attentiondeficit/hyperactivity disorder and addiction. $\mathrm{Br}$ J Clin Pharmacol 2012; 77: 337-56.

14. Martinez-Raga J, Knecht C, de Alvaro R, Szerman N, Ruiz P. Addressing dual diagnosis patients suffering from attention-deficit hyperactivity disorders and comorbid substance use disorders: A review of treatment considerations. Addict Disord Their Treat 2013; 12: 213-30.

15. Simon N, Rolland B, Karila L. Methylphenidate in adults with attention deficit hyperactivity disorder and substance use disorders. Curr Pharm Des 2015; 21: 3359-66.

16. Schubiner H, Saules KK, Arfken CL, et al. Double-blind placebo-controlled trial of methylphenidate in the treatment of adult ADHD patients with comorbid cocaine dependence. Exp Clin Psychopharmacol 2002; 10: 286-94.

17. Stahl SM. Stahl's Essential Psychopharmacology. 4th ed. Cambridge: Cambridge University Press, 2013.

18. Kooij JJS. Adult ADHD: Diagnostic assessment and treatment. 3rd ed. London: Springer-Verlag 2013.

19. Biederman J, Mick E, Surman C, et al. A randomized, placebo-controlled trial of OROS methylphenidate in adults with attentiondeficit/hyperactivity disorder. Biol Psychiatry 2006; 59: 829-35.

20. Casas M, Rösler M, Kooij JJS, et al. Efficacy and safety of prolonged-release OROS methylphenidate in adults with attention deficit/hyperactivity disorder: A 13-week, randomized, double-blind, placebo-controlled, fixed-dose study. World J Biol Psychiatry 2013; 14: 268-2\#81.

21. Konstenius M, Jayaram-Lindström N, Beck O, Franck J. Sustained release methylphenidate for the treatment of ADHD in amphetamine abusers: A pilot study. Drug Alcohol Depend 2010; 108: 130-3.

22. Konstenius M, Jayaram-Lindström N, Guterstam $J$, et al. Methylphenidate for attention deficit hyperactivity disorder and drug relapse in criminal offenders with substance dependence:
A 24-week randomized placebo-controlled trial. Addiction 2014; 109: 440-9.

23. Levin FR, Evans SM, Brooks DJ, Garawi F. Treatment of cocaine dependent treatment seekers with adult ADHD: Double-blind comparison of methylphenidate and placebo. Drug Alcohol Depend 2007; 87: 20-9.

24. Bradley, C. Benzedrine $\AA$ and Dexedrine $\AA$ in the treatment of children's behavior disorders. Pediatr 1950; 5: 24-37.

25. Faraone SV. Stimulant therapy in the management of ADHD: mixed amphetamine salts (extended release). Expert Opin on Pharmacother 2007; 8: 2127-34.

26. Weisler RH, Biederman J, Spencer TJ, et al. Mixed amphetamine salts extended-release in the treatment of adult ADHD: A randomized, controlled trial. CNS Spectr 2006; 11: 625-39.

27. Spencer TJ, Adler LA, Weisler RH, Youcha SH. Triple-bead mixed amphetamine salts (SPD465), a novel, enhanced extended-release amphetamine formulation for the treatment of adults with ADHD: A randomized, doubleblind, multicenter, placebo-controlled study. J Clin Psychiatry 2008; 69: 1437-48.

28. Biederman J, Spencer TJ, Wilens TE, et al. Long-term safety and effectiveness of mixed amphetamine salts extended release in adults with ADHD. CNS Spectr 2005; 10: 16-25.

29. Levin FR, Mariani JJ, Specker S, et al. Extended-release mixed amphetamine salts vs placebo for comorbid adult attention-deficit/ hyperactivity disorder and cocaine use disorder: A randomized clinical trial. JAMA Psychiatry 2015; 72: 593-602.

30. Faraone SV, Spencer T, Aleardi M, Pagano C, Biederman J. Meta-analysis of the efficacy of methylphenidate for treating adult attentiondeficit/hyperactivity disorder. J Clin Psychopharmacol 2004; 24: 24-9.

31. McLellan AT, Lewis DC, O'Brien CP, Kleber HD. Drug dependence, a chronic medical illness. JAMA 2000; 284: 1689.

32. Hewitt CE, Kumaravel B, Dumville JC, Torgerson DJ. Assessing the impact of attrition in randomized controlled trials. J Clin Epidemiol 2010; 63: 1264-70.

33. Leon AC, Mallinckrodt $\mathrm{CH}$, Chuang-Stein $\mathrm{C}$, et al. Attrition in randomized controlled clinical trials: Methodological issues in psychopharmacology. Biol Psychiatry 2006; 59: 1001-5. 
34. Parasrampuria DA, Schoedel KA, Schuller R, et al. Do formulation differences alter abuse liability of methylphenidate?: A placebocontrolled, randomized, double-blind, crossover study in recreational drug users. J Clin Psychopharmacol 2007; 27: 259-67.

35. Winhusen TM, Lewis DF, Riggs PD, et al. Subjective effects, misuse, and adverse effects of osmotic-release methylphenidate treatment in adolescent substance abusers with attention-deficit/hyperactivity disorder. J Child Adolesc Psychopharmacol 2011; 21: 455-63.

36. Manzi S, Law T, Shannon MW. Methylphenidate produces a false-positive urine amphetamine screen. Pediatr Emerg Care 2002; 18: 401.

37. Breindahl T, Hindersson P. Methylphenidate is distinguished from amphetamine in drug-ofabuse testing. J Anal Toxicol 2012; 36, 538-9.

38. Liberati A, Altman DG, Tetzlaff J, et al. The PRISMA statement for reporting systematic reviews and meta-analyses of studies that evaluate health care interventions: explanation and elaboration. Ann Intern Med 2009; 151: W65-W94.

39. García-Pérez MA. Accuracy and completeness of publication and citation records in the Web of Science, PsycINFO, and Google scholar: A case study for the computation of $h$ indices in psychology. J Am Soc Inf Sci Technol 2010; 61: 2070-85.

40. Higgins JPT, Green S. (editors). Cochrane Handbook for Systematic Reviews of Interventions Version 5.1.0 [updated March 2011]. The Cochrane Collaboration. Available at: http://training.cochrane.org/handbook. Assessed June 15, 2017.

41. Kaye S, Gilsenan J, Young JT, et al. Risk behaviours among substance use disorder treatment seekers with and without adult ADHD symptoms. Drug Alcohol Depend 2014; 144: 70-7.

42. Weiss M, Safren SA, Solanto MV, et al. Research forum on psychological treatment of adults with ADHD. J Atten Disord 2008; 11: 642-51.

43. Pang RD, Kirkpatrick MG, Goldenson NI, Guillot CR, Leventhal AM. Asians compared to Whites show increased response to $d$ amphetamine on select subjective and cardiovascular measures. Pharmacol Biochem
Behav 2016; 144: 73-7.

44. Brensilver M, Heinzerling KG, Shoptaw S. Pharmacotherapy of amphetamine-type stimulant dependence: An update. Drug Alcohol Rev 2013; 32: 449-60.

45. Castells X, Cunill R, Pérez-Mañá C, Vidal X, Capellà D. Psychostimulant drugs for cocaine dependence. Cochrane Database of Systematic Reviews 2016, Issue 9. Art. No.: CD007380.

46. Ledbetter M. Atomoxetine: A novel treatment for child and adult ADHD. Neuropsychiatr Dis Treat 2006; 2: 455-66.

47. Adler LA, Spencer T, Brown TE, et al. Oncedaily atomoxetine for adult attention-deficit/ hyperactivity disorder: a 6-month, doubleblind trial. J Clin Psychopharmacol 2009; 29: 44-50.

48. Sobanski E, Sabljic D, Alm B, et al. A randomized, waiting list-controlled 12-week trial of atomoxetine in adults with ADHD. Pharmacopsychiatry 2012; 45: 100-7.

49. McRae-Clark AL, Carter RE, Killeen TK, et al. A placebo-controlled trial of atomoxetine in marijuana-dependent individuals with attention deficit hyperactivity disorder. Am J Addict 2010; 19: 481-9.

50. Levin FR, Mariani JJ, Secora A, et al. Atomoxetine treatment for cocaine abuse and adult attention-deficit hyperactivity disorder (ADHD): A preliminary open trial. J Dual Diagn 2009: 5: 41-56. 